\title{
NOVO MÉTODO DE MENSURAR FIBRINOGÊNIO NO PLASMA DE CÃES
}

\author{
Andressa Aparecida Oggioni Pivari ${ }^{1}$ \\ Gabriel Ricardo de Souza Lima ${ }^{2}$ \\ Kamila Teixeira Pandolfi ${ }^{3}$ \\ Ronaldo Eugênio de Oliveira ${ }^{4}$ \\ Gabriela Porfírio-Passos ${ }^{5}$ \\ Lenir Cardoso Porfírio ${ }^{6}$
}

Resumo: O fibrinogênio (F) eleva-se mediante o estímulo de interleucinas e do fator de necrose tecidual liberados no processo inflamatório. Com o objetivo de propor uma nova técnica para quantificação desta proteína, propôs-se a técnica da diferença do plasma e soro e comparou-se os resultados com a Técnica de Precipitação Térmica (técnica convencional). Para a nova técnica, utilizou-se o sangue de 30 cães em tubos com e sem anticoagulante os quais foram centrifugados a 4000rpm por 10 minutos, e obteve-se o plasma e soro, respectivamente. Quantificou-se as proteínas de cada um em refratômetro e considerou-se a diferença entre o plasma e soro, como o fibrinogênio da amostra, expresso em $\mathrm{mg} \mathrm{dL}^{-1}$. Utilizando as mesmas amostras de sangue, comparou-se os resultados obtidos com a técnica convencional, que envolve mais etapas como banho-maria e centrifugações e obteve-se que correlação intraclasse dos valores médios do fibrinogênio pelas duas técnicas aplicadas para cães foi de 0.4747 , considerada uma replicabilidade de Média a Boa, sendo que a técnica proposta mostrou-se eficiente e de mais rápida para execução do exame. Palavras-chave: Refratometria; Precipitação de Proteína; Plasma; Soro.

\footnotetext{
${ }^{1}$ Medicina Veterinária/Universidade Federal do Espírito Santo, Brasil. E-mail: andressa.oggioni@gmail.com.

2 Medicina Veterinária/Universidade Federal do Espírito Santo, Brasil. E-mail: souzalima.gr@gmail.com.

3 Medicina Veterinária/Universidade Federal do Espírito Santo, Brasil. E-mail: kamilapandolfi@yahoo.com.br.

${ }^{4}$ Medicina Veterinária/Universidade Federal do Espírito Santo, Brasil. E-mail: ronaldo.oliveira@ufes.br.

${ }^{5}$ Medicina Veterinária/Universidade Federal do Espírito Santo, Brasil. E-mail: gporfiriopassos@gmail.com.

${ }^{6}$ Medicina Veterinária/Universidade Federal do Espírito Santo, Brasil. E-mail: lenircp52@gmail.com.
} 